\title{
Vaginal Cellular Angiofibroma with Heavy Bleeding: A Case Report
}

\author{
Anh Q. Nguyen ${ }^{1}$, Cassandra L. Presti ${ }^{1}$, Graham Nelsen ${ }^{1}$, Francine McLeod ${ }^{1,2}$ \\ ${ }^{1}$ Department of Obstetrics and Gynecology, Inova Fairfax Hospital, Falls Church, VA, USA \\ ${ }^{2}$ Department Obstetrics and Gynecology, School of Medicine, University of Virginia, Inova Campus, Falls Church, VA, USA \\ Email: anh.nguyen2@inova.org
}

How to cite this paper: Nguyen, A.Q. Presti, C.L., Nelsen, G. and McLeod, F. (2020) Vaginal Cellular Angiofibroma with Heavy Bleeding: A Case Report. Open Journal of Obstetrics and Gynecology, 10, 1609-1615.

https://doi.org/10.4236/ojog.2020.10110144

Received: September 28, 2020

Accepted: November 24, 2020

Published: November 27, 2020

Copyright $\odot 2020$ by author(s) and Scientific Research Publishing Inc. This work is licensed under the Creative Commons Attribution International License (CC BY 4.0).

http://creativecommons.org/licenses/by/4.0/

\begin{abstract}
Cellular angiofibroma is a rare mesenchymal tumor that most commonly presents as an asymptomatic well-circumscribed mass in the vulva. Very few cases have been found in the vagina and even fewer presented with vaginal bleeding. A 54-year-old female presented to the emergency department with five months of vaginal bleeding and symptomatic anemia requiring blood transfusion. Upon physical examination, she was found to have a firm $4 \mathrm{~cm}$ posterior vaginal mass, distinctly distal to the cervix. The mass was resected and diagnosed as a vaginal cellular angiofibroma on pathologic evaluation. The patient did well post-operatively with recommended follow-up every six months. The common differential diagnosis for a bleeding vaginal mass includes leiomyoma, angiofibroblastoma, aggressive angiomyxoma, squamous cell carcinoma, and adenocarcinoma. In this case, cellular angiofibroma presented as a vaginal mass with heavy bleeding leading to severe anemia. Early involvement of gynecologic oncology can help to optimize patients' evaluation and management.
\end{abstract}

\section{Keywords}

Vaginal Cellular Angiofibroma, Vaginal Tumor, Vaginal Bleeding

\section{Introduction}

Cellular angiofibroma is a rare mesenchymal tumor that can be found in both men and women. It was first described by Nucci et al. in 1997 through a series of four cases of soft tumor tissue of the vulva [1]. The tumors in this case series were small, well-circumscribed, and occurred in middle-aged women. Histologically, it is described as having the cellular spindle-cell component and prominent blood vessels. Though rare, a few case studies have been published and de- 
scribe cellular angiofibroma. In 2015, through literature review, Mandato et al. further characterized female cellular angiofibroma to have an asymptomatic presentation in the fifth decade of life in a somewhat different location: the vulvo-vaginal region with a few pelvic and extra-pelvic sites [2]. Of the total 79 cases that were reviewed, mean size of tumor was $3.6 \mathrm{~cm}$. Most lesions were in superficial soft tissues and a very small number involved the dermis. Cellular angiofibroma is considered benign with a very low risk of local recurrence and does not metastasize [3]. Local excision with negative margins is the treatment of choice for these lesions.

In women, cellular angiofibroma mainly occurs in the vulva and very rarely in the vagina [4]. A presentation of vaginal bleeding from cellular angiofibroma that requires blood transfusion is even more rare. Iwasa et al. reviewed 51 cases of female cellular angiofibroma and only identified one case with intermittent vaginal bleeding [5]. The purpose of this case report is to highlight a unique location and presentation of cellular angiofibroma. The patient was initially seen by the gynecology team at a community/academic hospital with her subsequent treatment plan jointly managed with gynecologic oncology. All post-operative visits were undertaken at our outpatient gynecologic oncology clinic.

\section{Case Presentation}

A 54-year-old Hispanic female, G5P3, with a past medical history of uterine fibroids presented to the emergency department with vaginal bleeding in the setting of a known vaginal mass. Her history was significant for abnormal uterine bleeding for five months. She described the bleeding as persistent and heavy. Her primary care physician noted a "cervical mass" and performed a Pap smear which resulted negative for intraepithelial lesion or malignancy. She was referred to an obstetrician gynecologist where she was found to have a $4.0 \times 4.0 \mathrm{~cm}$ posterior vaginal mass, distinct from the cervix. During the ensuing period of evaluation, the bleeding was unrelenting and unpredictable. This, coupled with her symptoms of weakness, dizziness, and shortness of breath, prompted her presentation to the emergency department.

Upon arrival to the emergency department, she was diagnosed with severe anemia with a hematocrit level of $22.2 \%$. Comparatively speaking, this was a significant decrease from a hematocrit level of $35.6 \%$ in the preceding month. She received fluid resuscitation and a blood transfusion. Transvaginal ultrasound revealed a $4.2 \times 3.9 \times 3.8 \mathrm{~cm}$ vascularized mass located in the vagina, concerning for carcinoma or vaginal fibroid (Figure 1). She was admitted to the hospital for surgical evaluation and consultation with gynecologic oncology.

On the patient's first day of admission, she underwent an exam under anesthesia and resection of the vaginal mass with a gynecologic oncologist. The exam revealed a $4.0 \times 4.0 \times 4.0 \mathrm{~cm}$ round, firm mass located in the upper third of the vagina approximately $2.0-3.0 \mathrm{~cm}$ distal to the cervix. The mucosa of the posterior vagina was incised and the mass was enucleated from the surrounding 


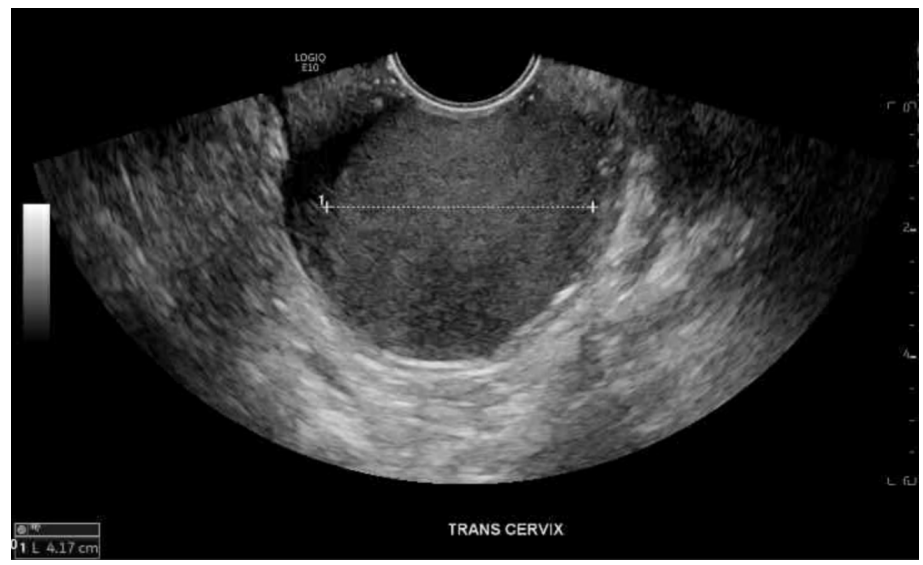

Figure 1. Transvaginal ultrasound of vaginal mass. The transvaginal ultrasound demonstrated a $4.2 \times 3.9 \times 3.8 \mathrm{~cm}$ vascularized mass located in the posterior vagina, that was noted to be separate from the cervix with movement of the ultrasound probe.

tissues. The rectovaginal septum remained intact, as was confirmed with proctoscopy. Her estimated blood loss with surgery was $50 \mathrm{~mL}$. The procedure was uncomplicated and the patient tolerated it well. She was discharged on the same day of her procedure in stable condition.

Pathologic evaluation of the vaginal mass revealed Mullerian stromal neoplasm with benign features, suggesting cellular angiofibroma (Figure 2). The tumor contained a more conspicuous collagen matrix than aggressive/deep angiomyxoma and lacked vascular smooth muscle proliferation typically encountered in the latter. The diagnosis of cellular angiofibroma was favored, and was confirmed by second opinion at the National Cancer Institute.

At her initial two-week post-operative appointment, the patient was doing well without any additional vaginal bleeding. She was instructed to remain on pelvic rest and return in one month. However, the patient was lost to follow-up and did not return to the clinic for three months. At her four-month post-operative visit, the patient reported abdominal cramping and hot flushes, but continued to deny any vaginal bleeding. On pelvic examination, her vaginal mucosa was well-healed. The patient's case was reviewed at our institution's tumor board, with the recommendation for follow up in the gynecologic oncology clinic every six months. During a telephone follow-up nine months post-operatively, she endorsed feeling well only having light vaginal bleeding for three days. She also reported mild discomfort near her vaginal incision, but declined any intervention or medication.

\section{Discussion}

Cellular angiofibromas in the vagina are rare, and only two cases have been reported in the literature that presented with vaginal bleeding. In 2012, Sujatha et al. described a 20-year-old patient in India with a bleeding vaginal mass at 34 weeks of gestation [6]. The mass was resected at the time of her cesarean section and found to be an angiofibroma. In 2019, Arega et al. described a 17-year-old 


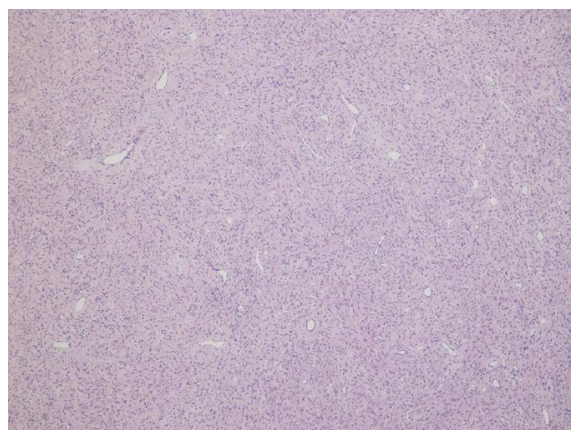

(a)

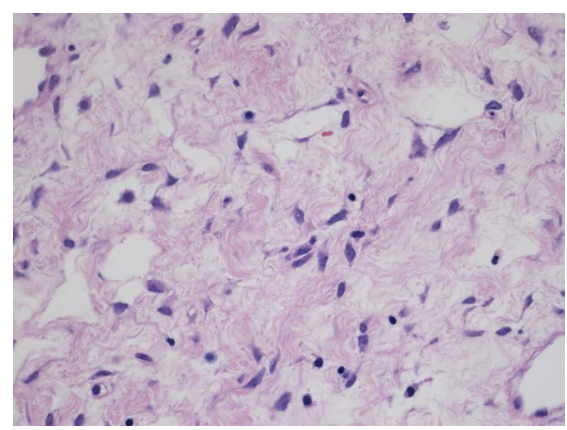

(b)

Figure 2. Pathologic diagnosis of cellular angiofibroma. Pathologic evaluation of the vaginal mass showed mullerian stroma with benign features favoring cellular angiofibroma. A mesenchymal neoplasm was grossly circumscribed and superficial in origin, with thin walled blood vessels. The tumor was composed of a mixture spindle and stellate cells in a fibrocollagenous stroma, without pleomorphisms or mitotic figures. (a) 40× H \& E stain; (b) $400 \times$ H \& E stain.

patient in Ethiopia with 2 years of irregular bleeding and anemia also requiring blood transfusion. The final pathology confirmed a $14 \mathrm{~cm}$ angiofibroma [7]. In our case, the bleeding was subacute. However, due to her severe anemia, age, and history of poor compliance with medical care, we proceeded with immediate surgical intervention to impact her health and exclude malignancy.

The differential diagnosis for a bleeding vaginal mass includes leiomyoma, angiomyofibroblastoma, aggressive angiomyxoma, squamous cell carcinoma, and adenocarcinoma (Table 1). Leiomyomas are the most common benign mesenchymal tumors of the vagina, and typically present as an approximately $3 \mathrm{~cm}$ mass in 25 to 54-year-old women with vaginal bleeding and pain [8]. Additionally, angiomyofibroblastomas are benign vulvovaginal neoplasms in reproductive aged women that may present as a small well-circumscribed mass. However, angiomyofibroblastomas have no recurrence potential. Deep (aggressive) angiomyxomas have a higher recurrence rate of up to $30 \%-40 \%$, and they present as a vaginal mass in women in their fourth decade [8]. Even though primary cancers of the vagina are rare, and the lesions tend to appear more ulcerated or poorly demarcated, both squamous cell carcinoma and adenocarcinoma should be considered as a part of the differential diagnosis of bleeding vaginal masses [9] [10]. 
Table 1. Summary of differential diagnosis. Differential diagnosis of a vaginal mass, both benign and malignant.

\begin{tabular}{|c|c|c|c|c|}
\hline $\begin{array}{c}\text { Differential } \\
\text { diagnosis }\end{array}$ & Age & Presentation & Malignancy & Recurrence \\
\hline Leiomyoma & 25 - 54 years & $\begin{array}{c}\text { Small }(<3 \mathrm{~cm}), \\
\text { tan-white, } \\
\text { well-circumscribed }\end{array}$ & Benign & None \\
\hline Leiomyosarcoma & $\begin{array}{c}\text { Average } 4^{\text {th }} \\
\text { decade }\end{array}$ & $\begin{array}{l}2-10 \mathrm{~cm}, \\
\text { infiltrative margin, } \\
\text { vaginal bleeding }\end{array}$ & Malignant & High \\
\hline Angiomyofibroblastoma & $\begin{array}{c}\text { Reproductive } \\
\text { age }\end{array}$ & $\begin{array}{c}\text { Small }(<5 \mathrm{~cm}), \\
\text { tan-white, } \\
\text { well-circumscribed }\end{array}$ & $\begin{array}{c}\text { Benign, } \\
\text { non-recurring }\end{array}$ & None \\
\hline Aggressive agiomyxoma & $\begin{array}{l}\text { Reproductive } \\
\text { age, median } \\
4^{\text {th }} \text { decade }\end{array}$ & $\begin{array}{l}\text { Large }(>10 \mathrm{~cm}) \text {, } \\
\text { soft, white, poor } \\
\text { demarcation }\end{array}$ & Malignant & $\begin{array}{c}30 \%-40 \% \\
\text { recurrence } \\
\text { if not } \\
\text { completely } \\
\text { excised }\end{array}$ \\
\hline Squamous cell carcinoma & Postmenopausal & $\begin{array}{l}\text { Vaginal bleeding, } \\
\text { pain, infiltrative } \\
\text { tumor }\end{array}$ & Malignant & $\begin{array}{c}\text { Depends } \\
\text { on stage. Poor } \\
\text { survival rate }\end{array}$ \\
\hline Adenocarcinoma & $46-67$ years & $\begin{array}{l}\text { Polypoid to } \\
\text { papillary } \\
+/- \text { ulceration }\end{array}$ & Malignant & $\begin{array}{l}\text { Depends } \\
\text { on stage }\end{array}$ \\
\hline
\end{tabular}

Cellular angiofibromas should be added to the differential diagnosis. There are morphological and immunohistochemical overlaps between aggressive angiomyxoma and cellular angiofibroma that prompted a consultation from our institution's pathologist to a second pathologist at the National Cancer Institute. HMGA2 has been used as a marker for aggressive angiomyxoma [11] with debatable levels of sensitivity and specificity [12]. While the patient's tumor stained positive for HMGA2, the lack of histologic infiltration into surrounding tissues favored a cellular angiofibroma diagnosis instead of an aggressive angiomyxoma.

A gynecologic oncologist was consulted upon admission to the hospital given the broad differential diagnoses including malignancy. This consultation facilitated intact removal of the vaginal mass with frozen pathology evaluation for carcinoma. Additionally, it facilitated appropriate outpatient follow-up in our specialty clinic. In conclusion, this case highlights that cellular angiofibroma can rarely present as a vaginal mass with symptomatic anemia secondary to vaginal bleeding. Management with a multi-disciplinary team approach including early involvement of with gynecologic oncology in such inconspicuous cases is best practice for optimal outcomes.

\section{Conclusions}

1) Cellular angiofibroma rarely presents in the vagina.

2) The differential diagnosis for a bleeding vaginal mass should include leiomyoma, angiomyofibroblastoma, aggressive angiomyxoma, squamous cell 
carcinoma, adenocarcinoma, and angiofibroma.

3) Best practice involves early soliciation of gynecologic oncology to optimize patient care and improve surgical outcomes.

\section{Consent}

Informed consent was obtained for publication of the report and associated images.

\section{Conflicts of Interest}

The authors declare no conflicts of interest.

\section{References}

[1] Nucci, M.R., Granter, S.R. and Fletcher, C.D. (1997) Cellular Angiofibroma: A Benign Neoplasm Distinct from Angiomyofibroblastoma and Spindle Cell Lipoma. The American Journal of Surgical Pathology, 21, 636-644. https://doi.org/10.1097/00000478-199706000-00002

[2] Mandato, V.D., Santagni, S., Cavazza, A., Aguzzoli, L., Abrate, M. and La Sala, G.B. (2015) Cellular Angiofibroma in Women: A Review of the Literature. Diagnostic Pathology, 10, Article No. 114. https://doi.org/10.1186/s13000-015-0361-6

[3] Nucci, M.R. and Fletcher, C.D. (2000) Vulvovaginal Soft Tissue Tumours: Update and Review. Histopathology, 36, 97-108. https://doi.org/10.1046/j.1365-2559.2000.00865.x

[4] Calonje, E., Brenn, T., Lazar, A. and McKee, P. (2011) McKee's Pathology of the Skin. Saunders, Philadelphia. https://www.clinicalkey.com/\#!/content/book/3-s2.0-B9780702069833000128

[5] Iwasa, Y. and Fletcher, C.D.M. (2004) Cellular Angiofibroma: Clinicopathologic and Immunohistochemical Analysis of 51 Cases. The American Journal of Surgical Pathology, 28, 1426-1435. https://doi.org/10.1097/01.pas.0000138002.46650.95

[6] Sujatha, V.V. and Veeragandham, S. (2012) Angiofibroma of Vagina during Pregnancy Presenting as Antepartum Haemorrhage: A Case Report. Journal of Clinical Gynecology and Obstetrics, 1, 28-29. https://doi.org/10.4021/jcgo2e

[7] Arega, C., Girma, W. and Sanchez Diaz, J.M. (2019) Angiofibroma of the Vagina Presenting with Abnormal Vaginal Bleeding: A Case Report from Ethiopia and Review of the Literature. Case Reports in Obstetrics and Gynecology, 2019, Article ID: 1486387.https://doi.org/10.1155/2019/1486387

[8] Nucci, M.R. and Oliva, E. (2009) Gynecologic Pathology. 2nd Edition, Elsevier Churchill Livingstone, London.

[9] Hoffman, B.L., Schorge, J.O., Bradshaw, K.D., Halvorson, L.M., Schaffer, J.I. and Corton, M.M. (2016) Vaginal Cancer. In: Williams Gynecology, 3e. McGraw-Hill Education, New York.

https://accessmedicine.mhmedical.com/content.aspx?bookid=1758\&sectionid=1181 $\underline{72818}$

[10] Siegel, R.L., Miller, K.D. and Jemal, A. (2015) Cancer Statistics, 2015. CA: A Cancer Journal for Clinicians, 65, 5-29. https://doi.org/10.3322/caac.21254

[11] McCluggage, W.G. (2009) Recent Developments in Vulvovaginal Pathology. Histopathology, 54, 156-173. https://doi.org/10.1111/j.1365-2559.2008.03098.x 
[12] McCluggage, W.G., Connolly, L. and McBride, H.A. (2010) HMGA2 Is a Sensitive but Not Specific Immunohistochemical Marker of Vulvovaginal Aggressive Angiomyxoma. The American Journal of Surgical Pathology, 34, 1037-1042. https://doi.org/10.1097/PAS.0b013e3181e32a11 